Article

\title{
Two LQRI based Blade Pitch Controls for Wind Turbines
}

\section{Sungsu Park ${ }^{1, *}$ and Yoonsu Nam ${ }^{2}$}

1 Department of Aerospace Engineering, Sejong University, Seoul 143-737, Korea

2 Department of Mechanical and Mechatronics Engineering, Kangwon National University, Kangwon 200-701, Korea; E-Mail: nys@kangwon.ac.kr

* Author to whom correspondence should be addressed; E-Mail: sungsu@sejong.ac.kr; Tel.: +82-2-3408-3769; Fax: +82-2-3408-3333.

Received: 15 February 2012; in revised form: 16 April 2012 / Accepted: 15 June 2012 /

Published: 20 June 2012

\begin{abstract}
As the wind turbine size has been increasing and their mechanical components are built lighter, the reduction of the structural loads becomes a very important task of wind turbine control in addition to maximum wind power capture. In this paper, we present a separate set of collective and individual pitch control algorithms. Both pitch control algorithms use the LQR control technique with integral action (LQRI), and utilize Kalman filters to estimate system states and wind speed. Compared to previous works in this area, our pitch control algorithms can control rotor speed and blade bending moments at the same time to improve the trade-off between rotor speed regulation and load reduction, while both collective and individual pitch controls can be designed separately. Simulation results show that the proposed collective and individual pitch controllers achieve very good rotor speed regulation and significant reduction of blade bending moments.
\end{abstract}

Keywords: wind turbine control; blade load reduction; collective pitch control; individual pitch control; Kalman filter; LQRI

\section{Introduction}

The main objective of wind turbine control is to make wind power production economically more efficient. This objective is often achieved in two distinct regions, i.e., the below rated wind speed and the above rated wind speed regions. In the below rated wind speed region, generator torque control is used primarily to control rotor speed to track the maximum power coefficient in order to maximize 
energy capture. In the above rated wind speed region, the blade pitch control is used primarily to regulate the rotor speed in order to regulate the aerodynamic power within its design limit [1]. As the wind turbine sizes are increasing and their mechanical components are built lighter, the reduction of the structural loads becomes a very important task of wind turbine control because structural loads can reduce turbine reliability and lifespan and also may cause power fluctuations. In particular, the reduction of blade loads has received special interest. Wind speed variations across the turbine rotor during rotor rotation, which is caused by the large rotor blade size, the wind shear, turbulence and tower shadow effects, cause periodic oscillations in blade structural loads, and this structural load is especially important in the above rated wind speed region because high structural loads arise from strong winds. Therefore the individual pitch control is sometimes considered since common collective pitch control cannot compensate for the periodic loads on the blades.

Individual pitch control has been investigated by a number of researchers and shown to be beneficial [2-18]. However, individual pitch control can reduce only the oscillation of blade bending moment, not its steady-state value. The collective pitch control can mitigate the magnitude of bending moments, but this is in conflict with the control objective of rotor speed regulation. A modern multi-input, multi-output (MIMO) control framework can be used to explicitly take into account the conflicted control objectives which are regulating rotor speed while reducing blade loads, and the so-called centralized pitch control can be designed where the collective and individual pitch commands are generated from the same controller [2-4]. The advantages of centralized pitch control include that it handles multiple control objectives. Although the design of centralized pitch control is desirable from the control point of view, the separate collective and individual pitch control system is still preferable to the majority of wind turbine industries since individual pitch control is considered as a secondary controller working as an on-off mechanism.

In this paper, we present a separate set of collective and individual pitch control algorithms. Both pitch control algorithms use the LQR control technique with integral action (LQRI), and utilize Kalman filters to estimate system states and wind speed [5-8,19]. Compared to previous works, our collective pitch controller can control the rotor speed and collective, i.e., the steady-state value of, blade bending moments together to improve the trade-off between rotor speed regulation and load reduction, while the individual pitch controller reduces the fluctuating loads on the blades. The individual pitch controller is designed separately as an additional loop around the system, and can be added on to the collective pitch controller. In this way, we utilize the advantages of both the central pitch control and the separate set of collective and individual pitch control systems. Our algorithm can compensate for the effect of wind disturbance and can reduce the blade loads significantly, while using the same blade bending moment measurements to those of previous works.

In the next section, the dynamics of the wind turbine is modeled as a time-varying system and is converted to two time-invariant systems for the collective and individual pitch controller designs respectively. In Section 3, the collective and individual pitch control algorithms are developed based on the LQRI and state estimation of the Kalman filter. The performance of control algorithms is evaluated in Section 4 using computer simulations, and conclusions follow in Section 5. 


\section{Wind Turbine Model}

A wind turbine is a highly nonlinear system and difficult to model. A very complex mathematical model containing several degrees of freedom is necessary to fully explore wind turbine system behavior. The wind turbine system under consideration in this paper is commercial 2 MW 3-bladed horizontal axis system. To model this wind turbine, the GH Bladed [20], commercial software, is used. The rotor blades are modeled with six modal frequencies in the flapwise direction and five modal frequencies in the edgewise direction. Tower motion is modeled with two modes both in fore-aft and side-side directions, respectively. The flexibility of the shaft connected to the rotor side is modeled by an equivalent spring constant and damping. The pitch actuator and generator torque dynamics are also modeled with second order and first order systems, respectively. This high fidelity model is used for simulations with the designed controller.

For the pitch controller design, a simple linear wind turbine model is required that sufficiently describes the dynamics of wind turbine. In this paper, the simple wind turbine model utilizes rigid rotor blades and drive-train, while tower is modeled by one mode of fore-aft motion and one mode of side-side motion $[3,9,10]$. Consider the blade coordinate system as shown in Figure 1(a), where the $\mathrm{x}$-axis points in the direction along the main shaft, the z-axis points toward the blade tip, the y-axis forms right-handed rule, and its origin is at the blade root. Consider also the fixed hub coordinate system as shown in Figure 1(b), where the x-axis points in the direction along the main shaft and the $\mathrm{z}$-axis is in an upward direction, and its origin is at the hub center.

Figure 1. (a) Blade coordinate system; (b) Fixed hub coordinate system [21].
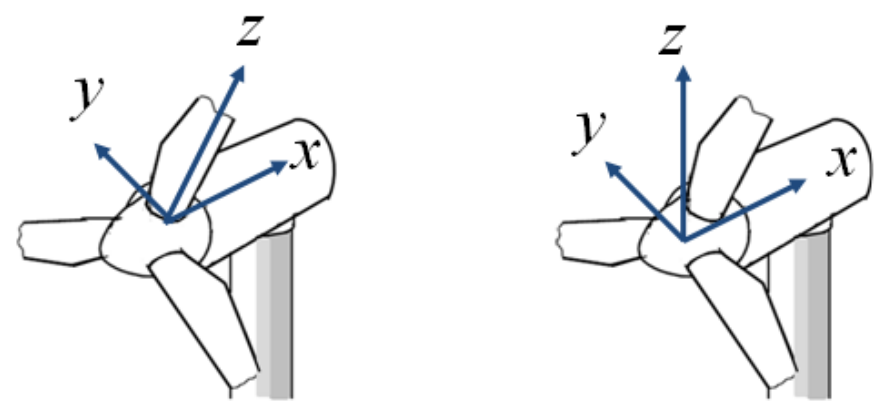

Then, the moments on the hub can be expressed using blade root moments as follows:

$$
\begin{aligned}
& M_{x}=\sum_{i=1}^{3} M_{x, i}^{b} \\
& M_{y}=\sum_{i=1}^{3} \cos \Psi_{i} M_{y, i}^{b} \\
& M_{z}=\sum_{i=1}^{3} \sin \Psi_{i} M_{y, i}^{b}
\end{aligned}
$$

where $\Psi_{i}$ is the blade azimuth angle defined as zero when the $i$-th blade is in the upward position, $M_{x, i}^{b}$ is the aerodynamic component of the $i$-th blade root moment in the x-axis, and $M_{y, i}^{b}$ is the measured $i$-th blade root moment in the y-axis of the blade coordinate system, and both are given as follows: 


$$
\begin{aligned}
& M_{x, i}^{b}=C_{M_{x}}\left(v_{i}, \Omega_{r}, \beta_{i}\right) \frac{1}{2} \rho \pi R_{b}^{2} v_{i}^{2} \\
& M_{y, i}^{b}=C_{M_{y}}\left(v_{i}, \Omega_{r}, \beta_{i}\right) \frac{1}{2} \rho \pi R_{b}^{2} v_{i}^{2}
\end{aligned}
$$

where $C_{M_{x}}$ and $C_{M_{v}}$ are the moment coefficients, $\Omega_{r}$ is the rotor speed, $\beta_{i}$ is the pitch angle of the $i$-th blade, $\rho$ is the air density, $R_{b}$ is the rotor radius, and $v_{i}$ is the relative wind speed for the $i$-th blade, which is the sum of the blade effective wind speed $v_{0, i}$ and tower fore-aft motion as follows [9]:

$$
v_{i}=v_{0, i}-\dot{x}_{f a}+\frac{3}{2 H} \frac{3 R_{b}}{4} \dot{x}_{f a} \cos \Psi_{i}
$$

where $H$ is the tower height and $x_{f a}$ is the tower fore-aft translation.

Similarly, the forces on the hub can be expressed as follows:

$$
\begin{aligned}
& F_{x}=\sum_{i=1}^{3} F_{x, i}^{b} \\
& F_{y}=\sum_{i=1}^{3} \cos \Psi_{i} F_{y, i}^{b}
\end{aligned}
$$

where $F_{x, i}^{b}$ and $F_{y, i}^{b}$ are the aerodynamic components of the $i$-th blade forces in the x-and y-axis of blade coordinate system respectively, and are also given as follows:

$$
\begin{aligned}
& F_{x, i}^{b}=C_{F_{x}}\left(v_{i}, \Omega_{r}, \beta_{i}\right) \frac{1}{2} \rho \pi R_{b}^{2} v_{i}^{2} \\
& F_{y, i}^{b}=C_{F_{y}}\left(v_{i}, \Omega_{r}, \beta_{i}\right) \frac{1}{2} \rho \pi R_{b}^{2} v_{i}^{2}
\end{aligned}
$$

where $C_{F_{x}}$ and $C_{F_{y}}$ are the force coefficients.

Since the wind turbine model is highly nonlinear, it has to be linearized at some operating point for the controller design. The moments on the hub can be linearized as follows:

$$
\begin{aligned}
& \delta M_{x}=\sum_{i=1}^{3}\left(\frac{\partial M_{x}^{b}}{\partial v} \delta v_{0, i}+\frac{\partial M_{x}^{b}}{\partial \beta} \delta \beta_{i}\right)+3 \frac{\partial M_{x}^{b}}{\partial \Omega_{r}} \delta \Omega_{r}-3 \frac{\partial M_{x}^{b}}{\partial v} \dot{x}_{f a} \\
& \delta M_{y}=\sum_{i=1}^{3} \cos \Psi_{i}\left(\frac{\partial M_{y}^{b}}{\partial v} \delta v_{0, i}+\frac{\partial M_{y}^{b}}{\partial \beta} \delta \beta_{i}\right)-\frac{\partial M_{y}^{b}}{\partial v} \frac{27 R_{b}}{16 H} \dot{x}_{f a} \\
& \delta M_{z}=\sum_{i=1}^{3} \sin \Psi_{i}\left(\frac{\partial M_{y}^{b}}{\partial v} \delta v_{0, i}+\frac{\partial M_{y}^{b}}{\partial \beta} \delta \beta_{i}\right)
\end{aligned}
$$

where $\delta$ denotes the difference from equilibrium value. The forces on the hub can be linearized likewise as follows:

$$
\begin{aligned}
& \delta F_{x}=\sum_{i=1}^{3}\left(\frac{\partial F_{x}^{b}}{\partial v} \delta v_{0, i}+\frac{\partial F_{x}^{b}}{\partial \beta} \delta \beta_{i}\right)+3 \frac{\partial F_{x}^{b}}{\partial \Omega_{r}} \delta \Omega_{r}-3 \frac{\partial F_{x}^{b}}{\partial v} \dot{x}_{f a} \\
& \delta F_{y}=\sum_{i=1}^{3} \cos \Psi_{i}\left(\frac{\partial F_{y}^{b}}{\partial v} \delta v_{0, i}+\frac{\partial F_{y}^{b}}{\partial \beta} \delta \beta_{i}\right)-\frac{\partial F_{y}^{b}}{\partial v} \frac{27 R_{b}}{16 H} \dot{x}_{f a}
\end{aligned}
$$


With the assumption of a rigid drive-train, the linearized rotor angular acceleration is described as:

$$
J_{e} \delta \dot{\Omega}_{r}=\delta M_{x}-N_{g} \delta T_{g}
$$

where $J_{e}$ is the effective moment of inertia of rotor, generator and transmission, $N_{g}$ is the gear ratio, and $\delta T_{g}$ is the perturbed generator torque. The tower motion is approximated by one mode of fore-aft and one mode of side-side motion as follows:

$$
\begin{aligned}
& M_{t} \ddot{x}_{f a}+D_{t} \dot{x}_{f a}+K_{t} x_{f a}=\delta F_{x}+\frac{3}{2 H} \delta M_{y} \\
& M_{t} \ddot{y}_{s s}+D_{t} \dot{y}_{s s}+K_{t} y_{s s}=\delta F_{y}+\frac{3 N_{g}}{2 H} \delta T_{g}
\end{aligned}
$$

where $M_{t}, D_{t}, K_{t}$ are tower modal mass, damping and stiffness, respectively, and $y_{s s}$ is the tower side-side translation. The multiplier $3 /(2 H)$ is the ratio between displacement and rotation of the tower top, assumed that the tower is approximated with prismatic beam subjected to a bending force load [9].

Equations (6-9) describe wind turbine dynamic equations and show that the wind turbine has time-varying dynamics even under constant wind conditions. To make the control design problem time-invariant, the time-varying wind turbine model is transformed to a linear time-invariant model using the Coleman transform. The Coleman transform and its inversion are defined as [22]:

$$
\begin{aligned}
& P=\left[\begin{array}{lll}
1 & \cos \Psi_{1} & \sin \Psi_{1} \\
1 & \cos \Psi_{2} & \sin \Psi_{2} \\
1 & \cos \Psi_{3} & \sin \Psi_{3}
\end{array}\right] \\
& P^{-1}=\left[\begin{array}{ccc}
1 / 3 & 1 / 3 & 1 / 3 \\
(2 / 3) \cos \Psi_{1} & (2 / 3) \cos \Psi_{2} & (2 / 3) \cos \Psi_{3} \\
(2 / 3) \sin \Psi_{1} & (2 / 3) \sin \Psi_{2} & (2 / 3) \sin \Psi_{3}
\end{array}\right]
\end{aligned}
$$

where $\Psi_{2}=\Psi_{1}+2 \pi / 3$ and $\Psi_{3}=\Psi_{1}+4 \pi / 3$.

Transforming perturbed wind speed, pitch angles and blade moments in Equations (6) and (7) to the variables in the Coleman frame yields the following moment equations:

$$
\begin{aligned}
& \delta M_{x}=3 \frac{\partial M_{x}^{b}}{\partial v}\left(\delta v_{0 c}-\dot{x}_{f a}\right)+3 \frac{\partial M_{x}^{b}}{\partial \beta} \delta \beta_{c}+3 \frac{\partial M_{x}^{b}}{\partial \Omega_{r}} \delta \Omega_{r} \\
& \delta M_{0}=\frac{\partial M_{y}^{b}}{\partial v}\left(\delta v_{0 c}-\dot{x}_{f a}\right)+\frac{\partial M_{y}^{b}}{\partial \beta} \delta \beta_{c}+\frac{\partial M_{y}^{b}}{\partial \Omega_{r}} \delta \Omega_{r} \\
& \delta M_{d}=\frac{\partial M_{y}^{b}}{\partial v} \delta v_{0 d}+\frac{\partial M_{y}^{b}}{\partial \beta} \delta \beta_{d}-\frac{\partial M_{y}^{b}}{\partial v} \frac{9 R_{b}}{8 H} \dot{x}_{f a} \\
& \delta M_{q}=\frac{\partial M_{y}^{b}}{\partial v} \delta v_{0 q}+\frac{\partial M_{y}^{b}}{\partial \beta} \delta \beta_{q}
\end{aligned}
$$

and force equations: 


$$
\begin{aligned}
& \delta F_{x}=3 \frac{\partial F_{x}^{b}}{\partial v}\left(\delta v_{0 c}-\dot{x}_{f a}\right)+3 \frac{\partial F_{x}^{b}}{\partial \Omega_{r}} \delta \Omega_{r}+3 \frac{\partial F_{x}^{b}}{\partial \beta} \delta \beta_{c} \\
& \delta F_{y}=\frac{3}{2} \frac{\partial F_{y}^{b}}{\partial v} \delta v_{0 d}+\frac{3}{2} \frac{\partial F_{y}^{b}}{\partial \beta} \delta \beta_{d}-\frac{\partial F_{y}^{b}}{\partial v} \frac{27 R_{b}}{16 H} \dot{x}_{f a}
\end{aligned}
$$

where $\delta v_{0 c}$ and $\delta \beta_{c}$ are the perturbed collective wind speed and pitch angle respectively, $\delta v_{0 d}$ and $\delta v_{0 q}$ are the perturbed wind speed, $\delta \beta_{d}$ and $\delta \beta_{q}$ are the perturbed pitch angles, and $\delta M_{d}$ and $\delta M_{q}$ are the perturbed moments in the d-(tilt) and q-axis(yaw) of the Coleman frame, respectively, which are defined as follows:

$$
\left[\begin{array}{l}
\delta v_{0 c} \\
\delta v_{0 d} \\
\delta v_{0 q}
\end{array}\right]=P^{-1}\left[\begin{array}{l}
\delta v_{0,1} \\
\delta v_{0,2} \\
\delta v_{0,3}
\end{array}\right], \quad\left[\begin{array}{l}
\delta \beta_{c} \\
\delta \beta_{d} \\
\delta \beta_{q}
\end{array}\right]=P^{-1}\left[\begin{array}{l}
\delta \beta_{1} \\
\delta \beta_{2} \\
\delta \beta_{3}
\end{array}\right], \quad\left[\begin{array}{l}
\delta M_{0} \\
\delta M_{d} \\
\delta M_{q}
\end{array}\right]=P^{-1}\left[\begin{array}{l}
\delta M_{y, 1}^{b} \\
\delta M_{y, 2}^{b} \\
\delta M_{y, 3}^{b}
\end{array}\right]
$$

The effective wind speed of each blade varies due to wind shear, turbulence and tower shadow effects, which results in periodic blade loading with the rotation of the rotor (so-called 1p, $2 \mathrm{p}, \ldots$, etc. loading). According to Equation (13), the 1p blade loading is transformed into constant loading in the Coleman frame, and the reduction of $1 \mathrm{p}$ blade loading can be achieved by reducing the constant values of the load in the Coleman frame. From Equation (11), these values can be controlled mainly by $\delta \beta_{d}$ and $\delta \beta_{q}$, and are almost decoupled from the collective pitch control $\delta \beta_{c}$, while the rotor speed and the collective blade moment can be controlled mainly by $\delta \beta_{c}$. This means that the collective and the individual pitch controls can be designed separately for their own control objectives.

\section{Pitch Controller Design}

The time-invariant wind turbine dynamic Equations $(8,9,11,12)$ can be written in state-space form as follows:

$$
\begin{aligned}
& \dot{x}=A x+B u+G d \\
& z=C x+D u+F d
\end{aligned}
$$

where:

$$
\begin{gathered}
x=\left[\begin{array}{lllll}
\delta \Omega_{r} & x_{f a} & \dot{x}_{f a} & y_{s s} & \dot{y}_{s s}
\end{array}\right]^{T}, u=\left[\begin{array}{llll}
\delta \beta_{c} & \delta \beta_{d} & \delta \beta_{q} & \delta T_{g}
\end{array}\right]^{T} \\
d=\left[\begin{array}{llllll}
\delta v_{0 c} & \delta v_{0 d} & \delta v_{0 q}
\end{array}\right]^{T}, z=\left[\begin{array}{llll}
\delta \Omega_{r} & \delta M_{0} & \delta M_{d} & \delta M_{q}
\end{array}\right]^{T}
\end{gathered}
$$

The controller in this paper consists of three independent control loops: generator torque control, collective pitch control, and individual pitch control. The generator torque control is maintained constant at the above rated wind speed and the drive-train damper is included to damp the drive-train's torsional oscillation. The conventional PI-based collective pitch control is also designed for comparison purpose, which includes some low-pass filter and notch filter. However, the design of the conventional collective pitch controller is not within the scope of this paper. The collective and individual pitch controllers are designed in this paper.

As discussed in the previous section and from Equations (8) and (11), the collective wind speed and pitch angle mainly affect the rotor speed and the collective blade moments, while the d- and q-axis wind speeds and pitch angles mainly affect the d-and q-axis blade moments. Therefore, Equation (14) 
can be decomposed into two sets of equations. One equation based on the assumption that all $\mathrm{d}$ - and q-axis variables are zero in Equation (14) is given as follows:

$$
\begin{aligned}
& \dot{x}=A x+B_{1} u_{1}+G_{1} d_{1} \\
& z_{1}=C_{1} x+D_{1} u_{1}+F_{1} d_{1}
\end{aligned}
$$

where:

$$
u_{1}=\delta \beta_{c}, d_{1}=\delta v_{0 c}, z_{1}=\left[\begin{array}{ll}
\delta \Omega_{r} & \delta M_{0}
\end{array}\right]^{T}
$$

and the other equation based on the assumption that all collective variables are zero is given as follows:

$$
\begin{aligned}
& \dot{x}=A x+B_{2} u_{2}+G_{2} d_{2} \\
& z_{2}=C_{2} x+D_{2} u_{2}+F_{2} d_{2}
\end{aligned}
$$

where:

$$
u_{2}=\left[\begin{array}{ll}
\delta \beta_{d} & \delta \beta_{q}
\end{array}\right]^{T}, d_{2}=\left[\begin{array}{ll}
\delta v_{0 d} & \delta v_{0 q}
\end{array}\right]^{T}, z_{2}=\left[\begin{array}{ll}
\delta M_{d} & \delta M_{q}
\end{array}\right]^{T}
$$

From Equations (14-16), it is clear that the system state variables $x$ cannot be used directly as measurements for control feedback because the state variables in Equations (15) and (16) are different from those of Equation (14). The state variables in Equation (15) are influenced only by the collective wind speed and pitch angle, and those in Equation (16) by the d- and q-axis wind speeds and pitch angles, respectively, whereas the variables in Equation (14) are influenced by all of them. Therefore, instead of measuring the state variables, we should estimate those variables from measured rotor speed $\delta \Omega_{r}$ and moment $\delta M_{0}$ in the case of Equation (15), and measured moments $\delta M_{d}$ and $\delta M_{q}$ in the case of Equation (16).

\subsection{Collective Pitch Controller}

The collective pitch controller is designed based on the dynamic Equation (15), where the inputs are the collective pitch angle $\delta \beta_{c}$ with the collective wind speed $\delta v_{0 c}$, and the measured outputs are the rotor speed $\delta \Omega_{r}$ and moment $\delta M_{0}$. The collective wind speed is estimated here and used by the pitch controller. The wind speed $d_{1}$ in Equation (15) can be modeled as an unknown constant with the addition of white noise of power spectral density $W_{1}$ as follows:

$$
\dot{d}_{1}=w_{1}, w_{1} \sim\left(0, W_{1}\right)
$$

Now, the Kalman filter is designed to estimate system states and wind speed based on the following augmented system with the wind speed:

$$
\begin{aligned}
& {\left[\begin{array}{c}
\dot{x} \\
\dot{d}_{1}
\end{array}\right]=\left[\begin{array}{cc}
A & G_{1} \\
0 & 0
\end{array}\right]\left[\begin{array}{c}
x \\
d_{1}
\end{array}\right]+\left[\begin{array}{c}
B_{1} \\
0
\end{array}\right] u_{1}+\left[\begin{array}{l}
0 \\
1
\end{array}\right] w_{1}} \\
& z_{1}=\left[\begin{array}{ll}
C_{1} & F_{1}
\end{array}\right]\left[\begin{array}{l}
x \\
d_{1}
\end{array}\right]+D_{1} u_{1}+v_{1}
\end{aligned}
$$

where $v_{1}$ is the measurement noise with the power spectral density of $V_{1}$.

Based on the state estimates, the LQR controller is designed, such that time domain performance criteria as minimal rotor speed variation and blade moment are directly included in the design. Since 
the standard LQR provides only proportional gains, Equation (15) is augmented with the integral of the rotor speed in order to cancel steady-state errors for step wind disturbances. Let $\delta \Omega_{I}$ be the integral of the rotor speed $\delta \Omega_{r}$, then the augmented system becomes:

$$
\begin{aligned}
& {\left[\begin{array}{c}
\dot{x} \\
\delta \dot{\Omega}_{I}
\end{array}\right]=\left[\begin{array}{cc}
A & 0 \\
C_{0} & 0
\end{array}\right]\left[\begin{array}{c}
x \\
\delta \Omega_{I}
\end{array}\right]+\left[\begin{array}{c}
B_{1} \\
0
\end{array}\right] u_{1}} \\
& y_{1}=\left[\begin{array}{cc}
C_{1} & 0 \\
0 & 1
\end{array}\right]\left[\begin{array}{c}
x \\
\delta \Omega_{I}
\end{array}\right]+\left[\begin{array}{c}
D_{1} \\
0
\end{array}\right] u_{1}
\end{aligned}
$$

where $C_{0}=\left[\begin{array}{lllll}1 & 0 & 0 & 0 & 0\end{array}\right]$, and $y_{1}$ is the performance output. The LQRI based collective pitch control is determined such that it minimizes the cost function:

$$
J=\int_{0}^{\infty}\left(y_{1}^{T} Q_{1} y_{1}+u_{1}^{T} R_{1} u_{1}\right) d t
$$

where the trade-off between rotor speed regulation and blade load reduction can be explicitly considered in the weighting matrix $Q_{1}$.

The collective pitch control command is calculated in a straight forward manner as follows:

$$
\delta \beta_{c}^{c m d}=K_{X c o l} \hat{x}+K_{I c o l} \int_{0}^{t} \delta \Omega_{\mathrm{r}} d t
$$

where $\hat{x}$ is the state estimate from the Kalman filter.

\subsection{Individual Pitch Controller}

The individual pitch controller is designed based on the dynamic Equation (16), where the inputs are the d-and q-axis pitch angles $\delta \beta_{d}, \delta \beta_{q}$ with the wind speeds $\delta v_{0 d}, \delta v_{0 q}$, and the measured outputs are d- and q-axis blade moments $\delta M_{d}, \delta M_{q}$.

Because the $1 \mathrm{p}$ variation of wind speed is transformed into a constant in the Coleman frame, the wind speeds $d_{2}$ in Equation (16) can be modeled as unknown constants with the addition of white noise of power spectral density $W_{2}$ as follows:

$$
\dot{d}_{2}=w_{2}, w_{2} \sim\left(0, W_{2}\right)
$$

The Kalman filter is designed based on the following augmented system with wind speeds:

$$
\begin{aligned}
& {\left[\begin{array}{c}
\dot{x} \\
\dot{d}_{2}
\end{array}\right]=\left[\begin{array}{cc}
A & G_{2} \\
0 & 0
\end{array}\right]\left[\begin{array}{c}
x \\
d_{2}
\end{array}\right]+\left[\begin{array}{c}
B_{2} \\
0
\end{array}\right] u_{1}+\left[\begin{array}{c}
0 \\
I_{2}
\end{array}\right] w_{2}} \\
& z_{2}=\left[\begin{array}{ll}
C_{2} & F_{2}
\end{array}\right]\left[\begin{array}{c}
x \\
d_{2}
\end{array}\right]+D_{2} u_{2}+v_{2}
\end{aligned}
$$

where $I_{2}$ denotes the identity matrix and $v_{2}$ is the measurement noise with the power spectral density of $V_{2}$.

Feedforward compensation can be utilized for rejecting the load caused by wind disturbance. Since the Kalman filter provides an estimate of the wind speed, we can design a feedforward controller on assumption that the wind and pitch angles dominate the blade moments in Equation (16) as follows: 


$$
u_{2_{-} f f}=-D_{2}^{-1} F_{2} \hat{d}_{2}
$$

where $\hat{d}_{2}$ is wind speed estimate.

Again, since the standard LQR provides only proportional gains, Equation (16) is augmented with the integrals of the blade moments in order to cancel steady-state errors for step wind disturbances. Let $z_{I}$ be the integrals of the blade moments $z_{2}$, then the augmented system becomes:

$$
\begin{aligned}
& {\left[\begin{array}{c}
\dot{x} \\
\dot{z}_{I}
\end{array}\right]=\left[\begin{array}{cc}
A & 0 \\
C_{2} & 0
\end{array}\right]\left[\begin{array}{c}
x \\
z_{I}
\end{array}\right]+\left[\begin{array}{c}
B_{2} \\
D_{2}
\end{array}\right] u_{2}} \\
& y_{2}=\left[\begin{array}{cc}
C_{2} & 0 \\
0 & I_{2}
\end{array}\right]\left[\begin{array}{c}
x \\
z_{I}
\end{array}\right]+\left[\begin{array}{c}
D_{2} \\
0
\end{array}\right] u_{2}
\end{aligned}
$$

where $y_{2}$ is the performance output. The LQRI based individual pitch control is determined such that it minimizes the cost function:

$$
J=\int_{0}^{\infty}\left(y_{2}^{T} Q_{2} y_{2}+u_{2}^{T} R_{2} u_{2}\right) d t
$$

The time domain performance criteria as minimal fluctuation of blade moments are directly included in weighting matrices $Q_{2}$ and $R_{2}$.

Figure 2. Blade pitch control scheme.

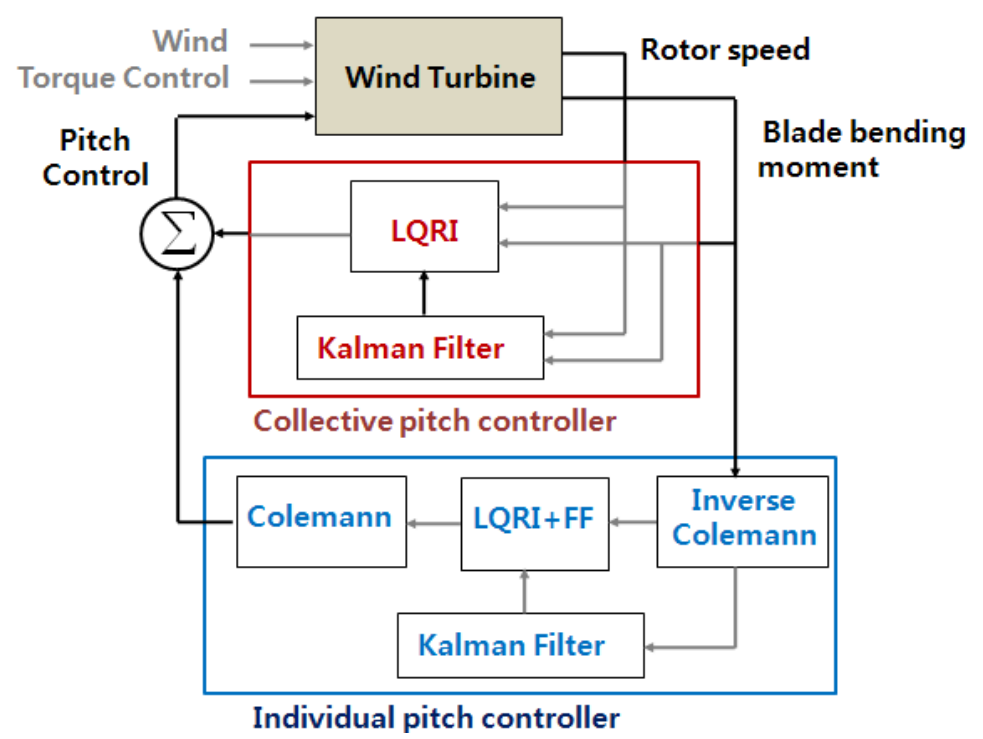

The feedback control law is calculated in a straight forward manner as follows:

$$
u_{2_{-} f b}=K_{X i p c} \hat{x}+K_{\text {Iipc }} \int_{0}^{t} z_{2} d t
$$

where $\hat{x}$ is the state estimate from the Kalman filter. The individual pitch control commands, $\delta \beta_{d}^{c m d}$ and $\delta \beta_{q}^{\text {cmd }}$, calculated in the Coleman frame are obtained by summing the feedback control (27) and the feedforward control (24), and these control commands are transformed to the pitch command for each blade by the Coleman transform before adding it to the collective pitch command. The overall pitch control commands for each blade are given as follows: 


$$
\begin{aligned}
& \delta \beta_{1}^{c m d}=\delta \beta_{c}^{c m d}+\delta \beta_{d}^{c m d} \cos \Psi_{1}+\delta \beta_{q}^{c m d} \sin \Psi_{1} \\
& \delta \beta_{2}^{c m d}=\delta \beta_{c}^{c m d}+\delta \beta_{d}^{c m d} \cos \Psi_{2}+\delta \beta_{q}^{c m d} \sin \Psi_{2} \\
& \delta \beta_{3}^{c m d}=\delta \beta_{c}^{c m d}+\delta \beta_{d}^{c m d} \cos \Psi_{3}+\delta \beta_{q}^{c m d} \sin \Psi_{3}
\end{aligned}
$$

The overall pitch control structure is shown schematically in Figure 2.

\section{Simulations}

The simplified linear model, which is used for the pitch controller design, is validated in Figures 3 and 4. In these figures, the first column shows the frequency responses of rotor speed of the high fidelity and simple turbine models to the three Coleman-transformed pitch angles and wind speeds. The second and the third columns are the frequency responses for the $\mathrm{d}$ - and q-axis blade moments, respectively. The frequency response plots of the high fidelity and simple turbine models show that the simple linear wind turbine model is an appropriate choice for the pitch controller design.

Figure 3. Frequency response from Coleman-transformed pitch angles to rotor speed, $\mathrm{d}$ - and q-axis blade moments, both for the high fidelity (red) and the simple models (blue).

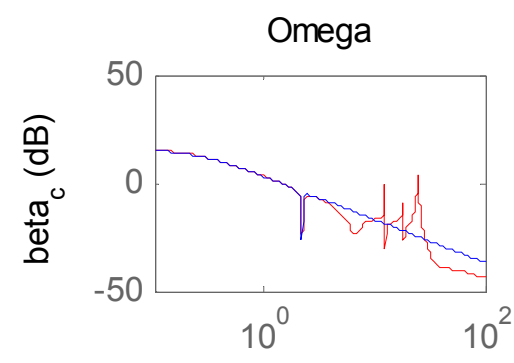

Frequency (rad/sec)

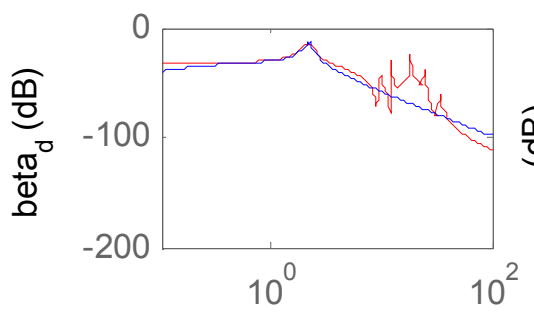

Frequency (rad/sec)

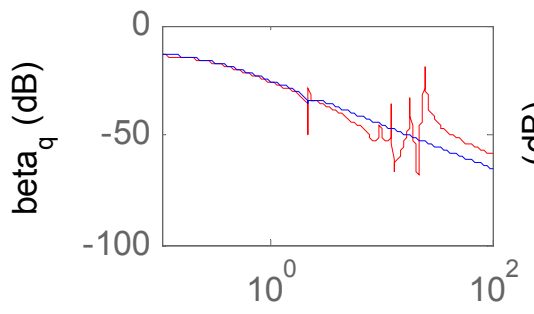

Frequency ( $\mathrm{rad} / \mathrm{sec})$

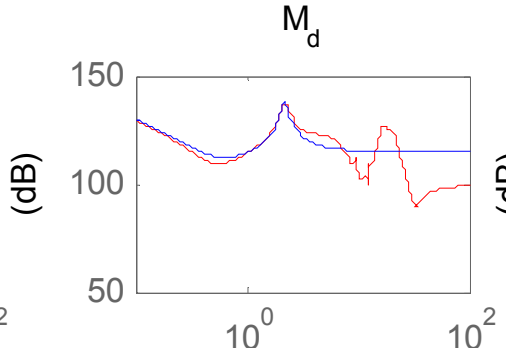

Frequency (rad/sec)

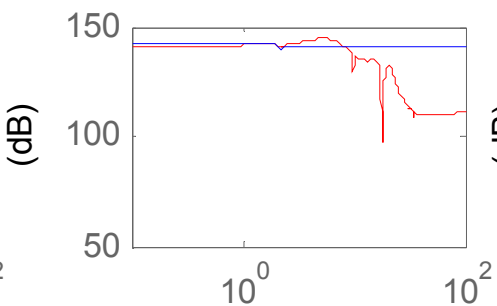

Frequency ( $\mathrm{rad} / \mathrm{sec})$

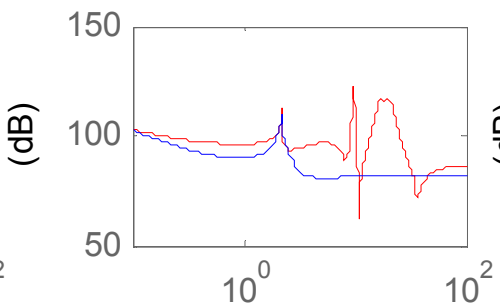

Frequency ( $\mathrm{rad} / \mathrm{sec})$

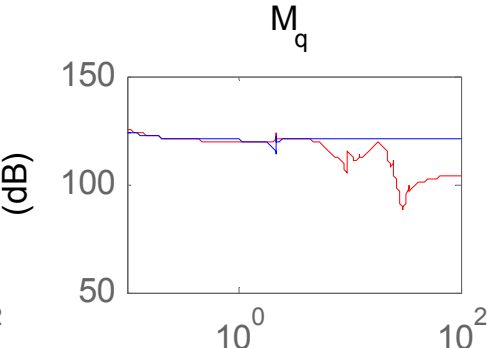

Frequency (rad/sec)

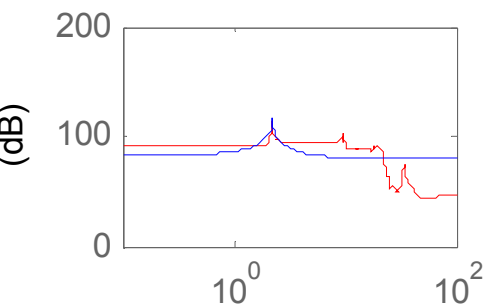

Frequency (rad/sec)

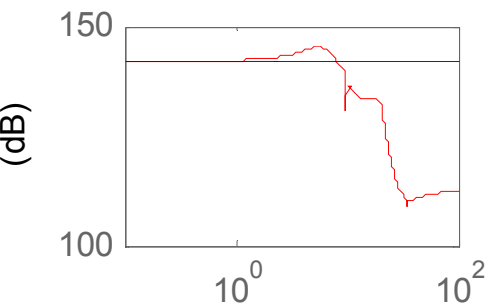

Frequency ( $\mathrm{rad} / \mathrm{sec}$ ) 
Figure 4. Frequency response from Coleman-transformed wind speeds to rotor speed, d- and q-axis blade moments, both for the high fidelity (red) and the simple models (blue).
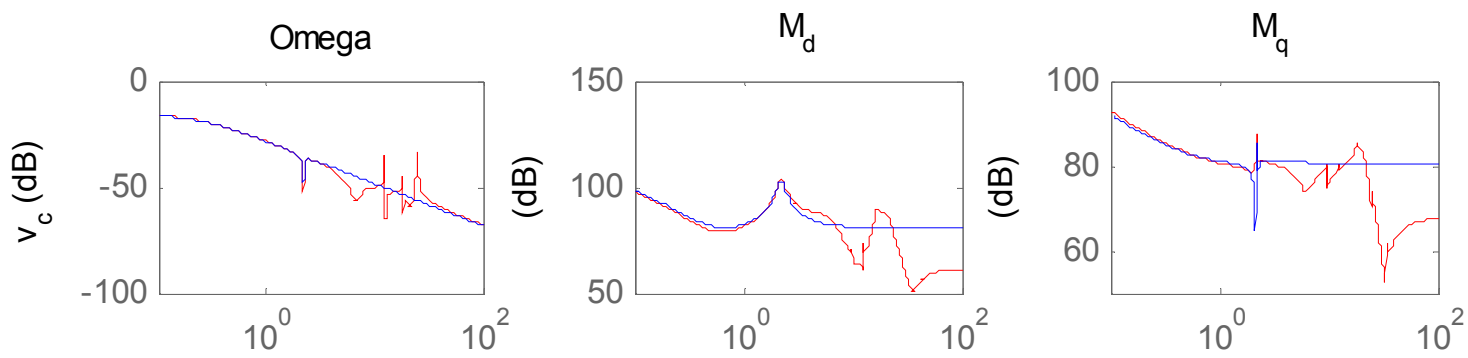

Frequency ( $\mathrm{rad} / \mathrm{sec})$

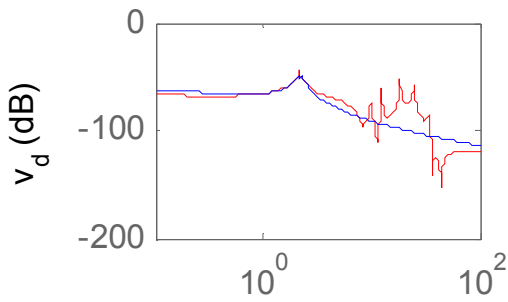

Frequency (rad/sec)

Frequency (rad/sec)
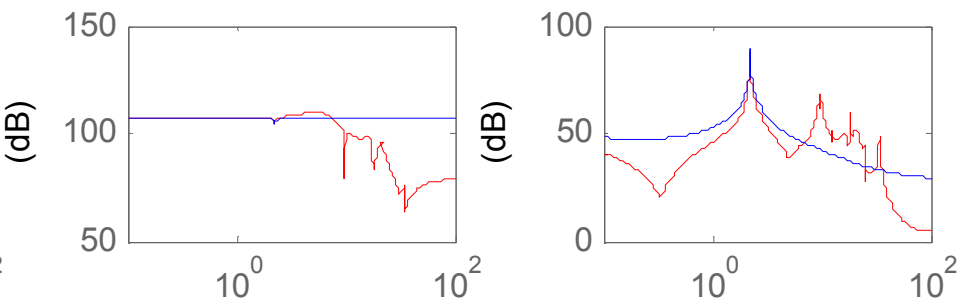

Frequency ( $\mathrm{rad} / \mathrm{sec})$

Frequency (rad/sec)

Frequency (rad/sec)

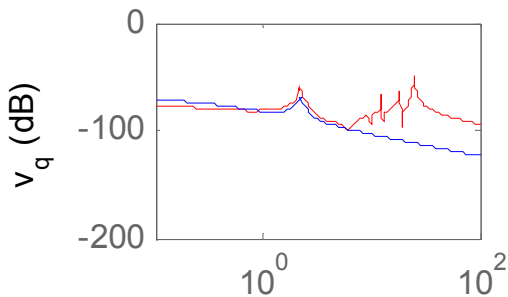

Frequency (rad/sec)
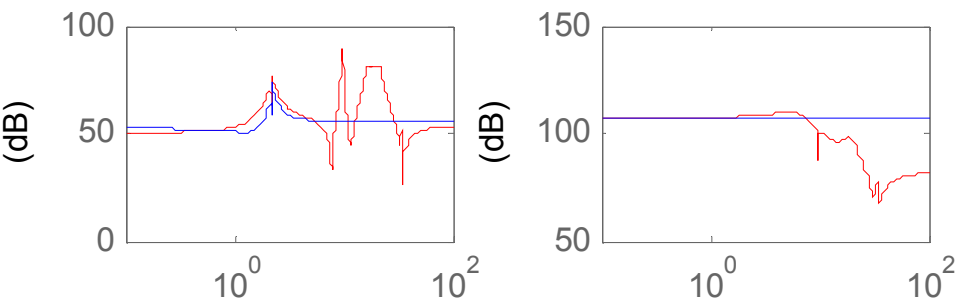

Frequency (rad/sec)

Frequency (rad/sec)

Figure 5. Wind speed profile.

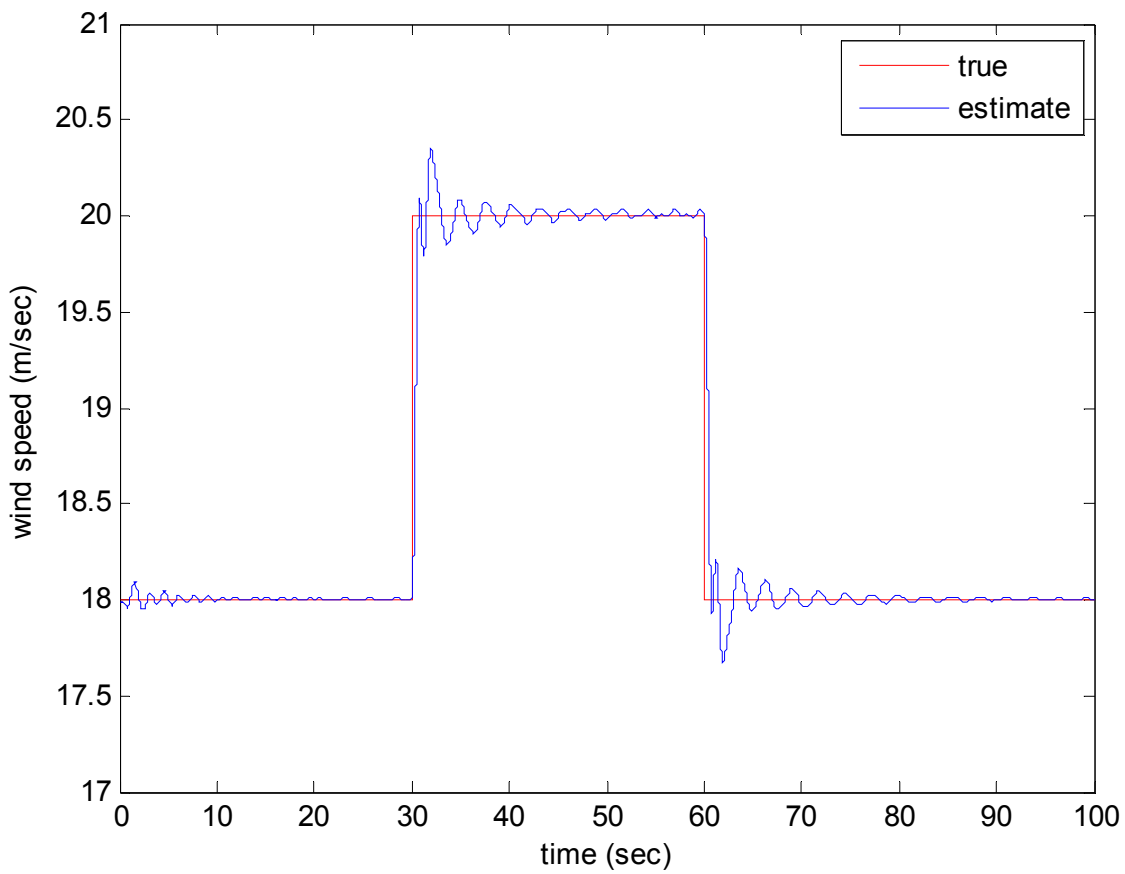


Computer simulations are performed to evaluate the performance of the proposed collective and individual pitch controllers. The high fidelity wind turbine model described in Section 2 is used for simulations, and the drive-train damper is designed and implemented beforehand.

Two wind conditions are used in simulations. First, the steady wind with positive stepwise change shown in Figure 5 is considered and a wind shear is superimposed on the wind field. In Figure 5, the estimate of wind speed is also plotted. Although the wind speed profile in Figure 5 is unrealistic, it offers very clear view of the wind turbine dynamic behavior.

The trade-off between rotor speed regulation and blade load reduction is made and the results are shown in Figures 6-9. This trade-off is possible because the rotor speed regulation and blade load reduction are explicitly considered in the cost function. These figures also show the performance of individual pitch control compared to that of collective pitch control alone. From Figures 6 and 7, it can be seen that good regulation performance of rotor speed leads to significant overshoot in the blade loads. In other words, the rotor speed is well regulated and quickly compensated for the influences of wind speed changes, but it produces a large overshoot of collective blade bending moments when putting more weightings on the rotor speed regulation, however, the collective blade bending moments responds moderately at the cost of large overshoot and slow response of rotor speed when putting more weightings on the blade load reduction. For comparison purpose, the rotor speed and collective bending moment responses of the conventional PI-based collective pitch control are also plotted in Figures 6 and 7. Although conventional collective pitch control regulates rotor speed well, it produces a large overshoot of collective blade bending moments. Figures 6 and 7 also show that the individual pitch control does not significantly affect the rotor speed and bending moment responses, which explains the decoupling between the collective and individual pitch controls.

Figure 6. Responses of rotor speed (more weighting on blade moment(blue), more weighting on rotor speed(red), PI-based control(black)): (a) without IPC; (b) with IPC.

(a)

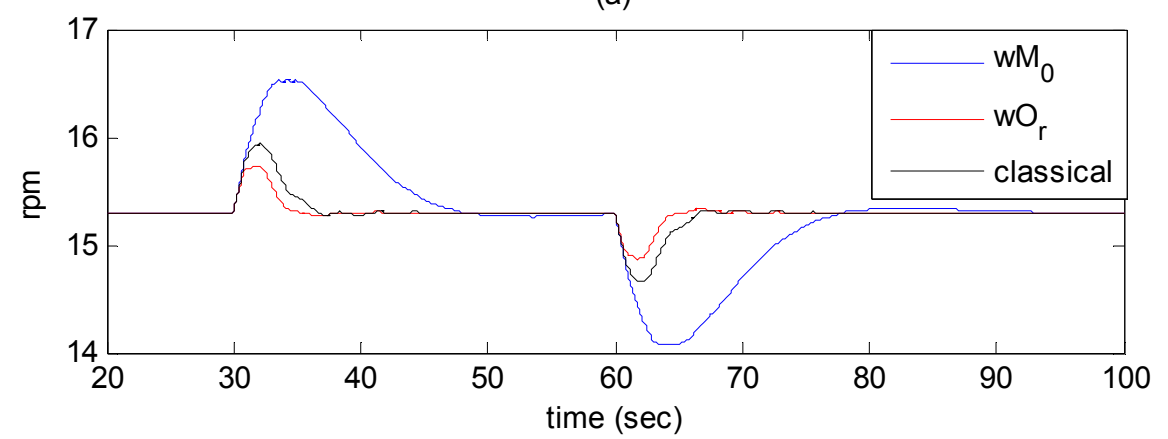

(b)

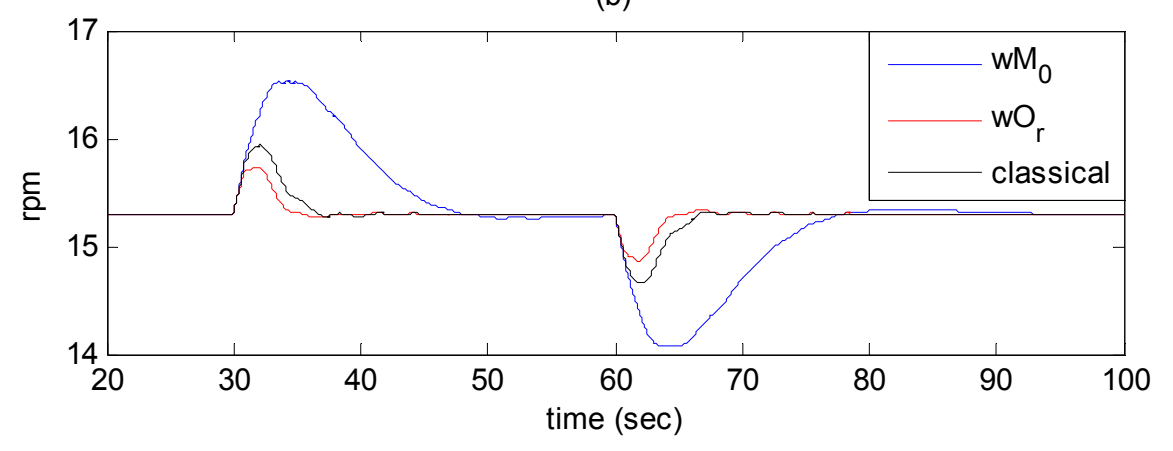


Figure 7. Responses of collective blade bending moments: (a) without IPC; (b) with IPC.
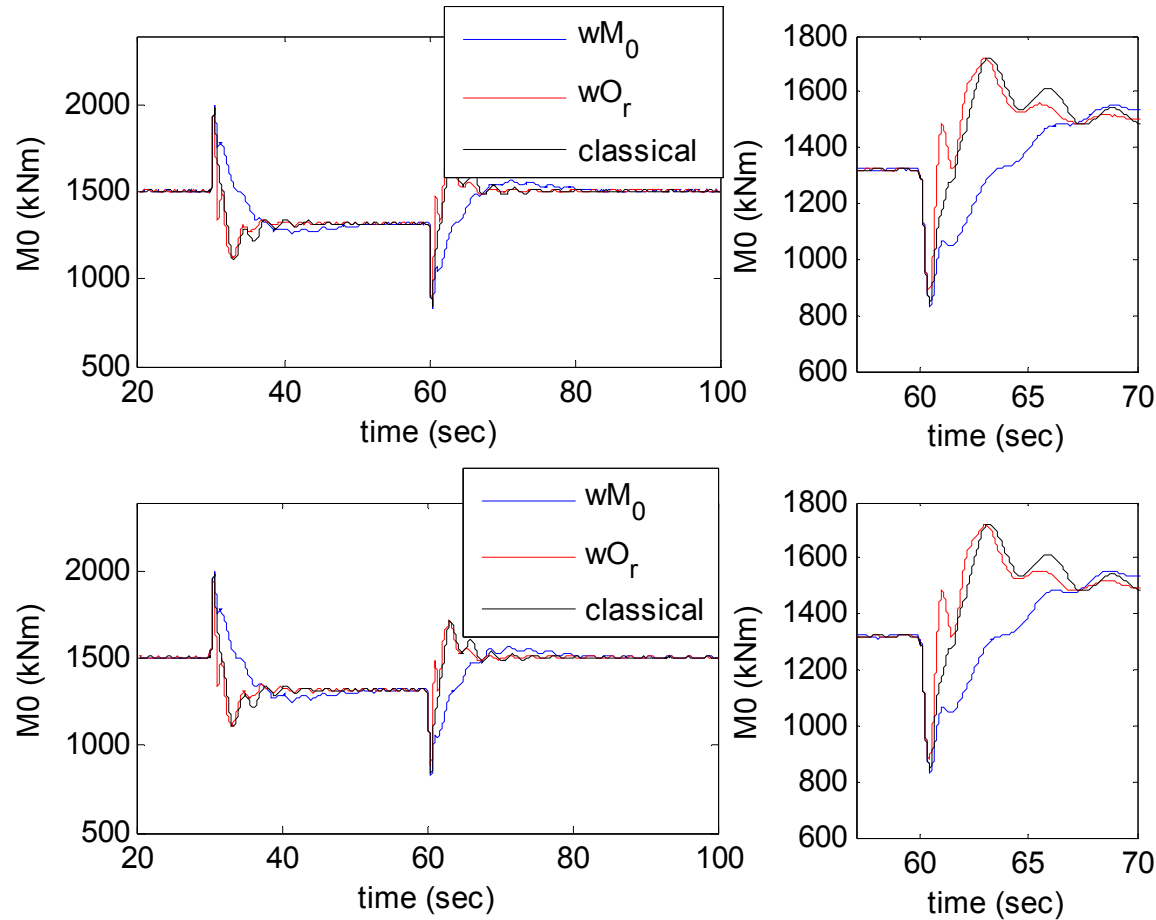

Figure 8 shows the responses of the blade bending moments. The individual pitch controllers achieve a significant reduction of blade bending moment oscillations compared to the collective pitch control.

Figure 8. Responses of blade bending moments (without IPC (top) and with IPC (bottom)): (a) more weighting on blade moment; (b) more weighting on rotor speed.

(a)
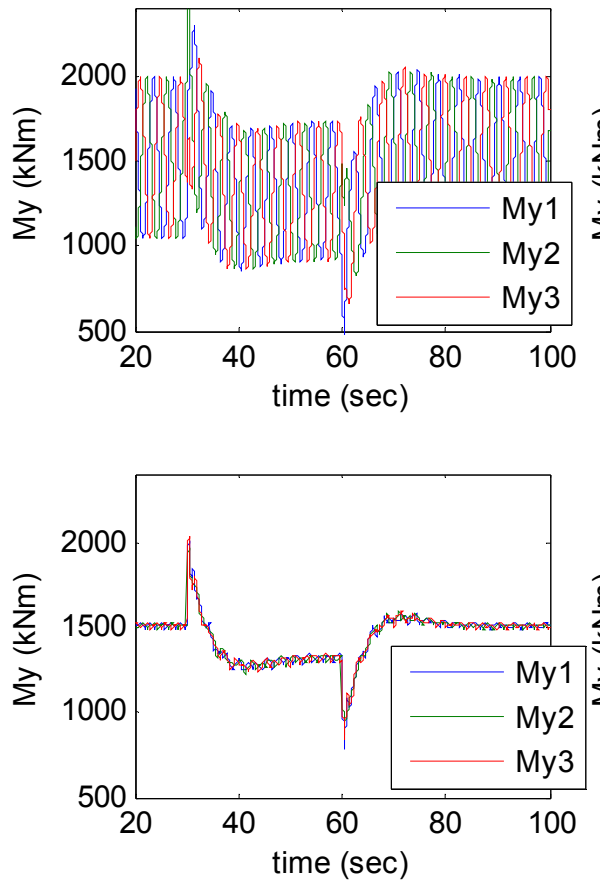

(b)
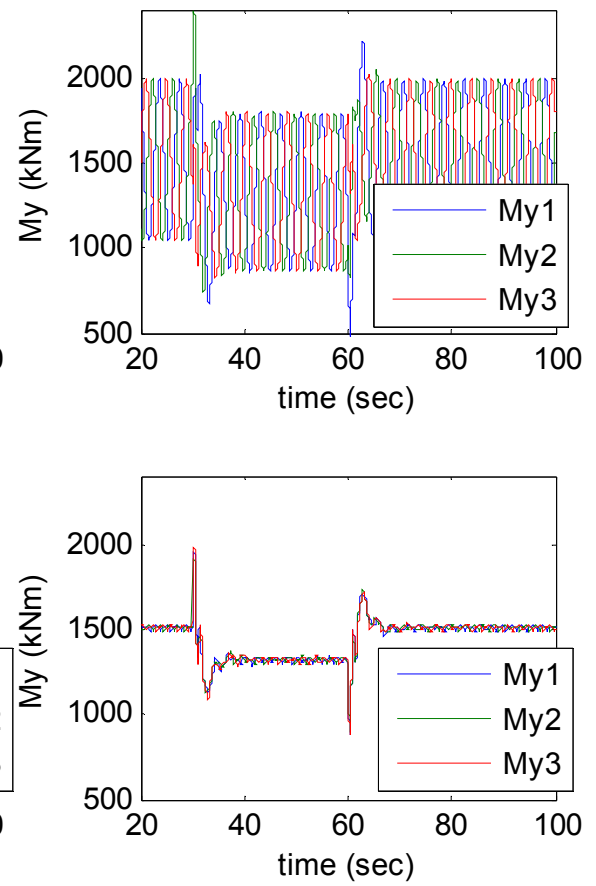
Figure 9 shows the associated blade pitch control commands for the collective and individual pitch controllers, and that the load reduction is a consequence of increased pitch activity that constantly varies around the collective pitch angle to control the periodic blade bending moments.

Figure 9. Responses of pitch commands (without IPC (top) and with IPC (bottom)): (a) more weighting on blade moment; (b) more weighting on rotor speed.

(a)
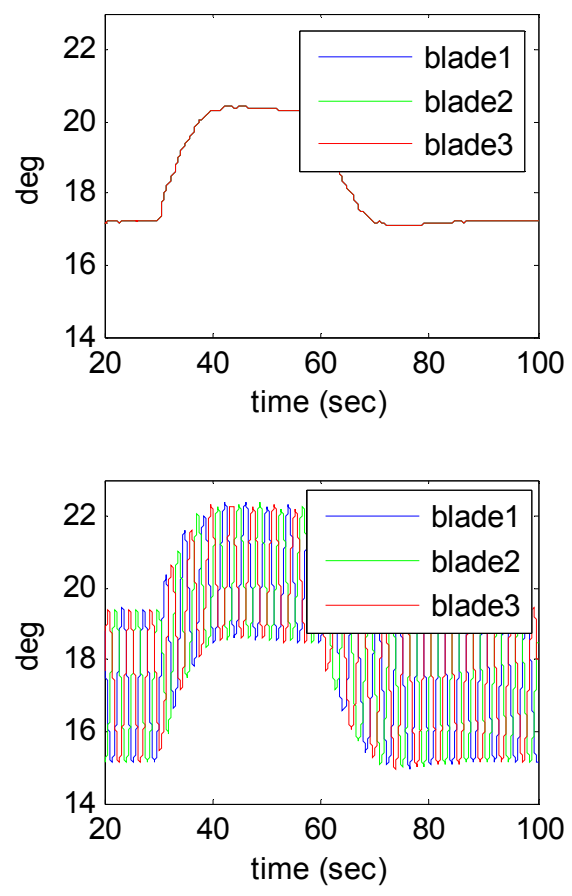

(b)
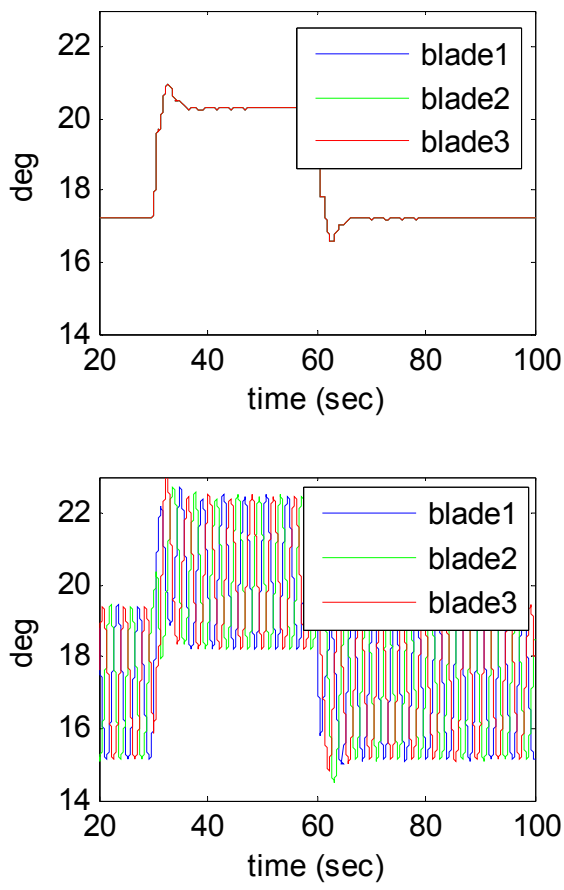

Figure 10. Turbulent wind speed profile.

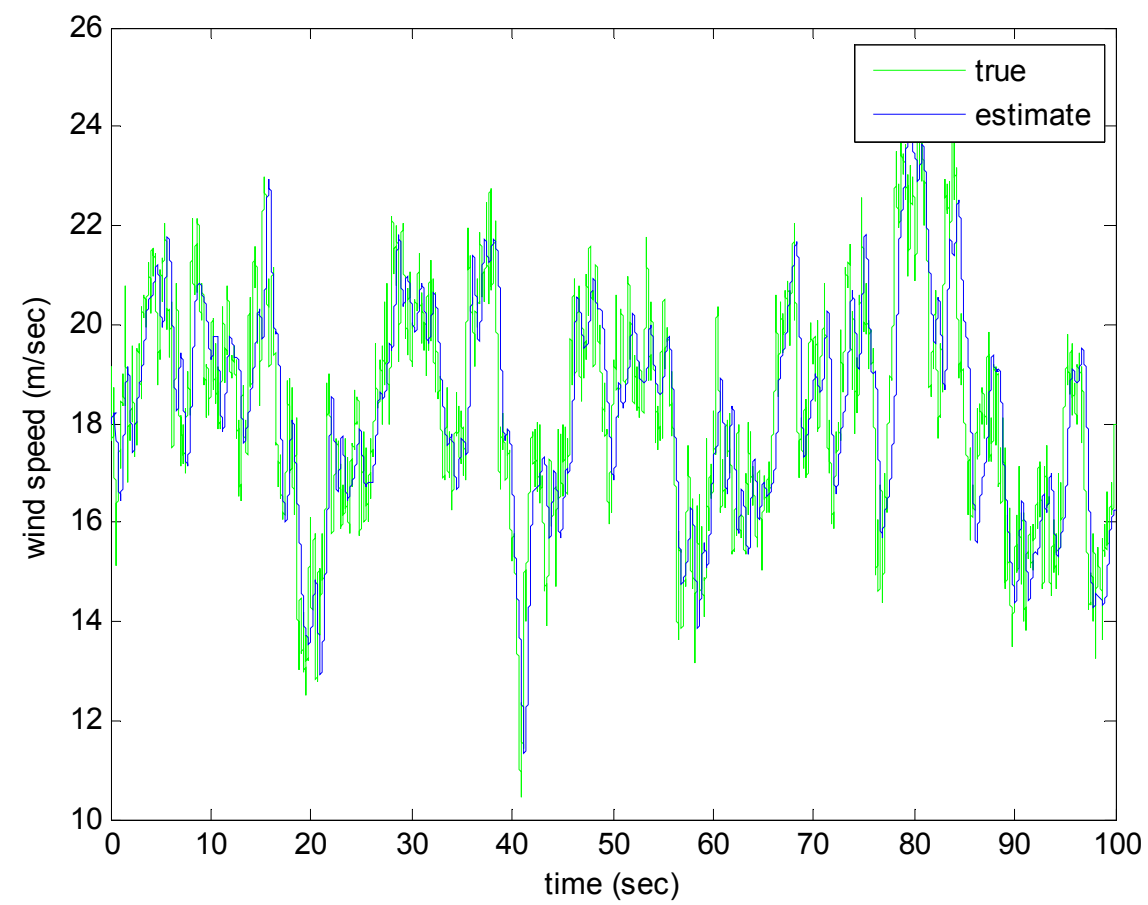


Figure 11. Responses of blade bending moments: (a) without IPC; (b) with IPC.

(a)

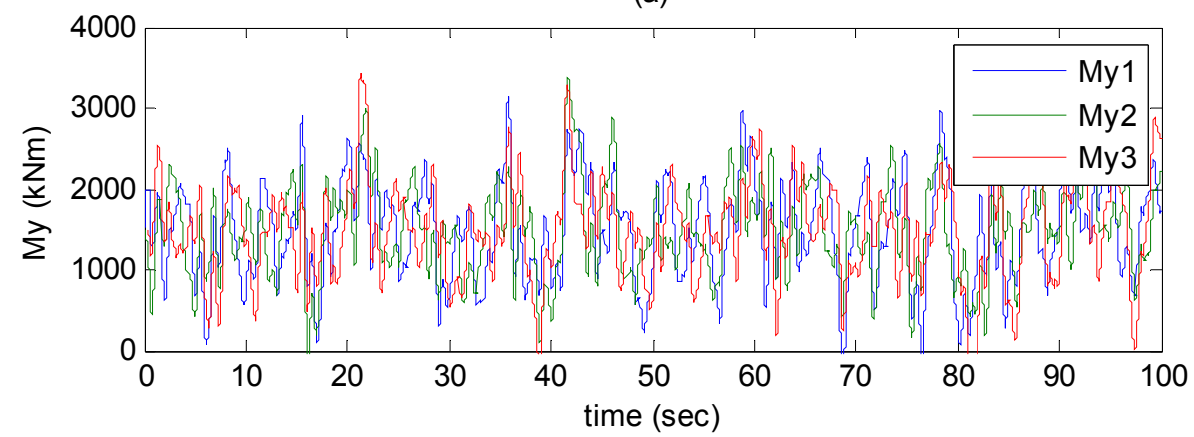

(b)

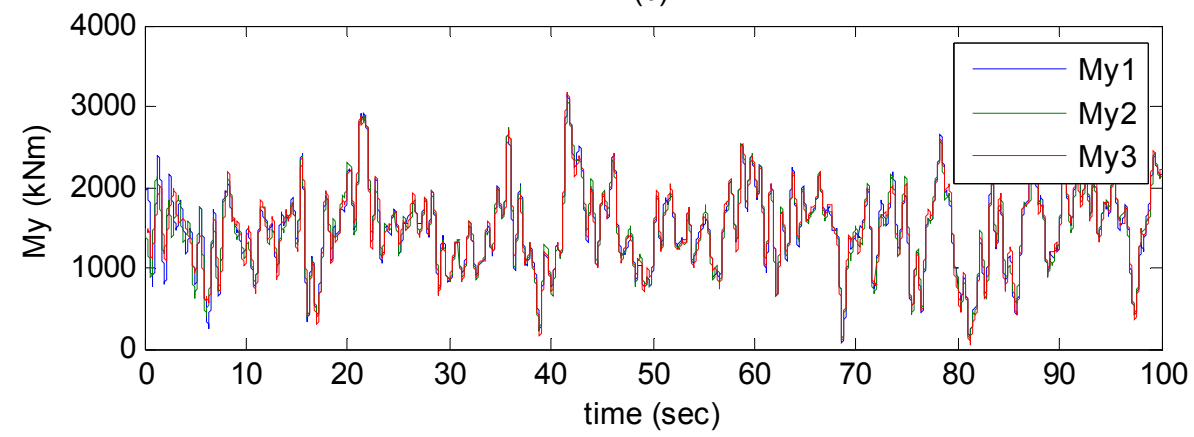

Figure 12. Responses of pitch commands: (a) without IPC; (b) with IPC.

(a)

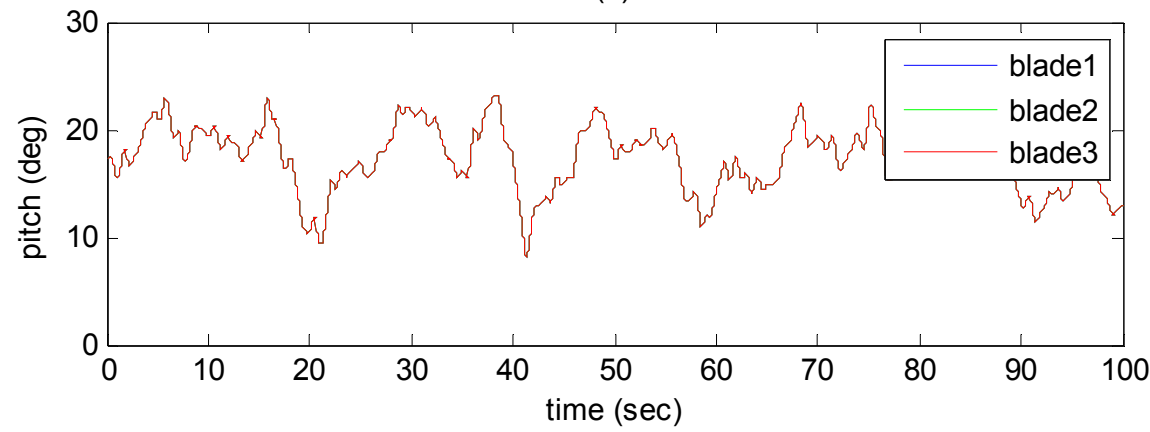

(b)

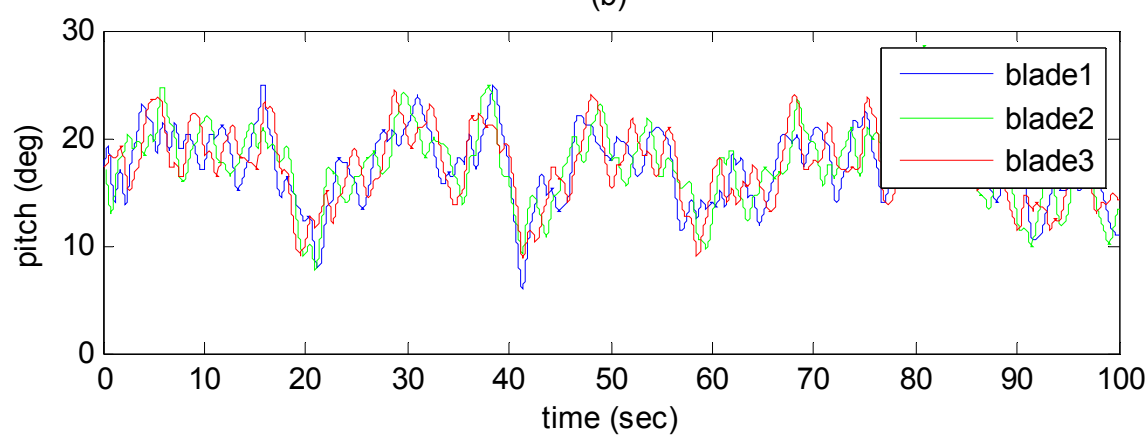

A more realistic turbulent wind $(\mathrm{TI}=18 \%$ ) condition shown in Figure 10 is used for the second simulation runs with the same controllers, and the simulation results are shown in Figures 11-13, where the responses of the blade bending moments, the pitch commands, and the rotor speed are shown. Transforming the blade bending moments to the collective, and d-(tilt) and q-axis (yaw) moments in the Coleman frame, the effect of the individual controller becomes very apparent as shown 
in Figure 14. For comparison purpose, the rotor speed and collective bending moment responses of the conventional collective pitch control are also plotted in Figures 13 and 14. Slightly larger fluctuations than those of the proposed collective pitch control are observed.

Figure 13. Responses of rotor speed.

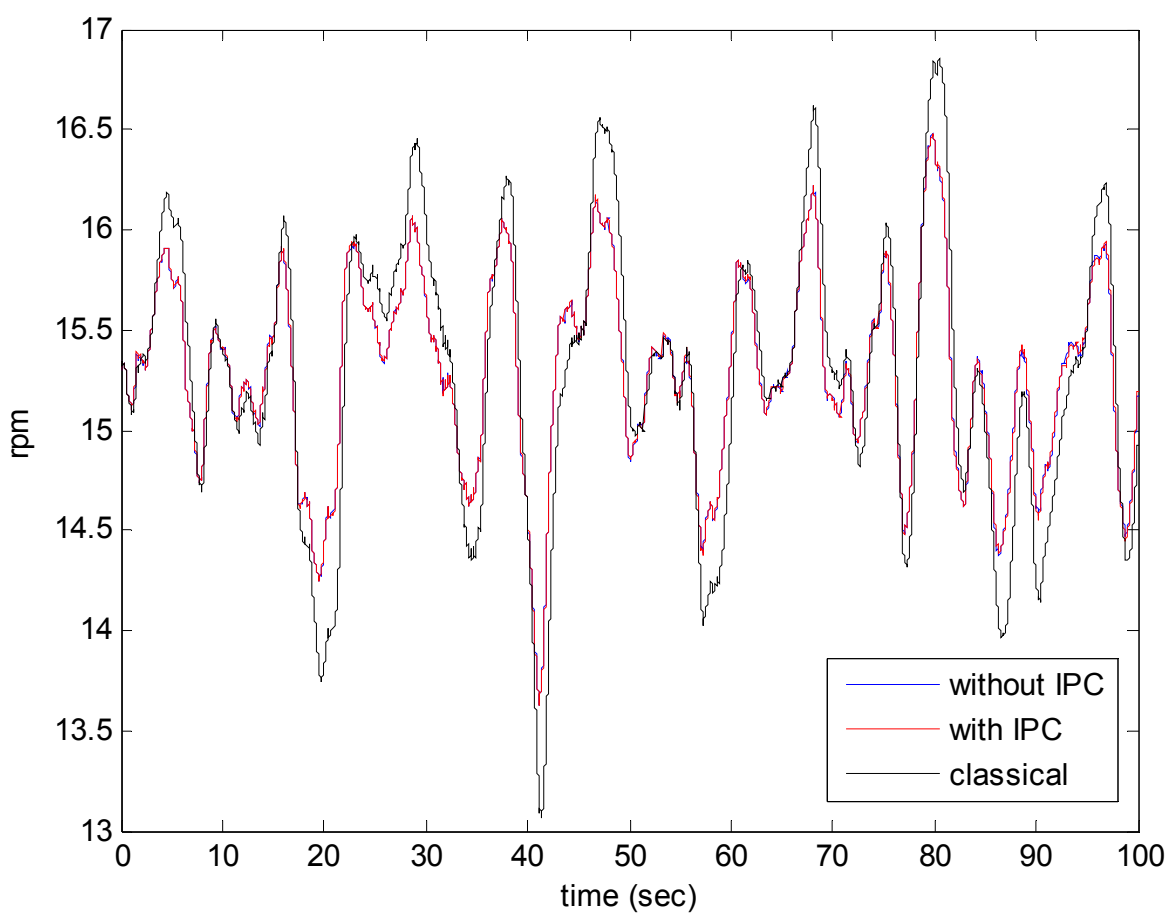

Figure 14. Responses of collective moment (top), tilt moment (middle) and yaw moment (bottom).
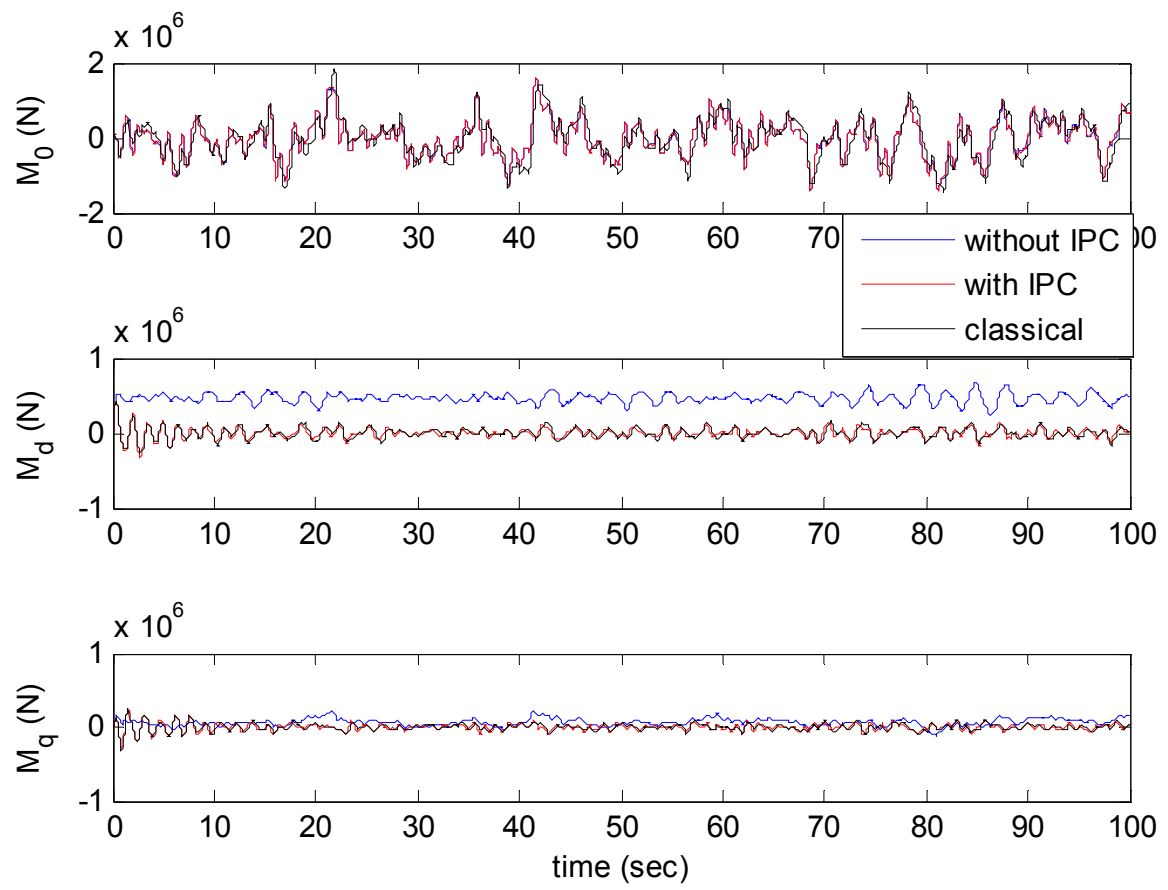
Considering all simulation cases, it can be seen that very good rotor speed regulation performance can be achieved, together with a significant reduction of blade bending moments by the proposed collective and individual pitch controllers.

\section{Conclusions}

In this paper, we presented separate sets of collective and individual pitch control algorithms for rotor speed regulation and blade load reduction for a wind turbine. The simple linear time-varying model was first derived by linearization, which is suitable for blade pitch controller design, but yet sufficiently describes the dynamics of wind turbine, and then converted into two time-invariant models by the Coleman transform for the collective and individual pitch controller designs.

With both the linear time-invariant models, the collective and individual pitch control algorithms were developed separately based on the LQRI and the state estimation of Kalman filter. Our algorithms take advantages of both central pitch control and the separate sets of collective and individual pitch control systems such that time domain performance criteria as rotor speed regulation and minimal bending moments can be directly included in the design and at the same time, both pitch control algorithms can be designed separately.

The states of both systems were estimated in the Coleman frame using Kalman filters, and these were used in the LQRI control. The collective pitch controller can control rotor speed and collective blade bending moments together to improve the trade-off between rotor speed regulation and load reduction, and the individual pitch controller can reduce the fluctuating loads on the blades. The collective pitch controller is a main controller, while the individual pitch control can be added to the collective pitch controller as an on-off mechanism.

Computer simulations were performed with a high fidelity model containing several degrees of freedom and steady and turbulent wind conditions. Simulation results showed that the proposed collective and individual pitch controllers achieved very good rotor speed regulation and significant reduction of blade bending moments.

\section{Acknowledgements}

This work was supported by the National Research Foundation of Korea (NRF) grant funded by the Korea government(MEST) (No. 2011-0012420).

\section{References}

1. Laks, J.H.; Pao, L.Y.; Wright, A.D. Control of Wind Turbines: Past, Present, and Future. In Proceedings of the American Control Conference, St. Louis, MO, USA, 10-12 June 2009; pp. 2096-2103.

2. Stol, K.A.; Zhao, W.; Wright, A.D. Individual blade pitch control for the controls advanced research turbine (cart). J. Sol. Energy Eng. 2006, 128, 498-505.

3. Selvam, K.; Kanev, S.; van Wingerden, J.W.; van Engelen, T.; Vergaegen, M. Feedback-feedforward individual pitch control for wind turbine load reduction. Int. J. Robust Nonlinear Control 2008, 130, 72-91. 
4. Thomsen, S.C.; Niemann, H.; Poulsen, N.K. Individual Pitch Control of Wind Turbines Using Local Inflow Measurements. In Proceedings of the 17th World Congress on the International Federation of Automatic Control, Seoul, Korea, 6-11 July 2008; pp. 5587-5592.

5. Munteanu, I.; Cutululisand, N.A.; Bratcu, A.I.; Ceanga, E. Optimization of variable speed wind power systems based on a LQG approach. Control Eng. Pract. 2005, 13, 903-912.

6. Lescher, F.; Camblong, H.; Briand, R.; Curea, O. Alleviation of Wind Turbines Loads with a LQG Controller Associated to Intelligent Micro Sensors. In Proceedings of the IEEE International Conference on Industrial Technology (ICIT 2006), Mumbai, India, 15-17 December 2006; pp. 654-659.

7. Nourdine, S.; Camblong, H.; Vechiu, I.; Tapia, G. Comparison of Wind Turbine LQG Controllers Designed to Alleviate Fatigue Loads. In Proceedings of the 8th IEEE International Conference on Control and Automation, Xiamen, China, 9-11 June 2010; pp. 1502-1507.

8. Selvam, K. Individual Pitch Control for Large Scale Wind Turbines; ECN-E-07-053; Energy Research Center of the Nertherlands: North Holland, The Nertherlands, 2007.

9. Petrovic, V.; Jelavic, M.; Peric, N. Identification of Wind Turbine Model for Individual Pitch Controller Design. In Proceedings of the 43rd International Universities Power Engineering Conference (UPEC 2008), Padova, Italy, 1-4 September 2008.

10. Jelavic, M.; Petrovic, V.; Peric, N. Estimation based individual pitch control of wind turbine. Automatika 2010, 51, 181-192.

11. Wilson, D.G.; Berg, D.E.; Resor, B.R.; Barone, M.F.; Berg, J.C. Combined Individual Pitch Control and Active Aerodynamic Load Controller Investigation for the $5 \mathrm{MW}$ Up Wind Turbine. In Proceedings of the AWEA WINDPOWER 2009 Conference \& Exhibition, Chicago, IL, USA, 4-7 May 2009.

12. Leithead, W.E.; Connor, B. Control of variable speed wind turbines: Design task. Int. J. Control 2000, 13, 1189-1212.

13. Balas, M.J.; Wright, A.; Hand, M.M.; Stol, K. Dynamics and Control of Horizontal Axis Wind Turbines. In Proceedings of the American Control Conference, Denver, CO, USA, 4-6 June 2003.

14. Wright, A.D. Modern Control Design for Flexible Wind Turbines; Technical Report NREL/TP-500-35816; National Renewable Energy Laboratory: Golden, CO, USA, 2004.

15. Ma, H.; Tang, G.; Zhao, Y. Feedforward and feedback optimal control for offshore structures subjected to irregular wave forces. Ocean Eng. 2006, 33, 1105-1117.

16. Bottasso, C.L.; Croce, A.; Savini, B. Performance comparison of control schemes for variable-speed wind turbines. J. Phys. Conf. Ser. 2007, 75, doi:10.1088/1742-6596/75/1/012079.

17. Wright, A.D.; Fingersh, L.J. Advanced Control Design for Wind Turbines; Technical Report NREL/TP-500-42437; National Renewable Energy Laboratory: Golden, CO, USA, 2008.

18. Van Engelen, T. Design Model and Load Reduction Assessment for Multi-rotational Mode Individual Pitch Control (Higher Harmonics Control); ECN-RX-06-068; Energy Research Centre of the Netherlands: North Holland, The Nertherlands, 2006.

19. Mateljak, P.; Petrovic, V.; Baotic, M. Dual Kalman Estimation of Wind Turbine States and Parameters. In Proceedings of the International Conference on Process Control, Tatranská Lomnica, Slovakia, 14-17 June 2011; pp. 85-91. 
20. Bossanyi, E.A.; Quarton, D.C. GH Bladed-Theory Manual; Garrad Hassan \& Partners Ltd.: Bristol, UK, 2008.

21. Lloyd, G. Rules and Guidelines IV: Industrial Services, Part I-Guideline for the Certification of Wind Turbines, 5th ed.; Germanischer Lloyd Windenergie: Hamburg, Germany, 2003.

22. Bir, G. Multiblade Coordinate Transformation and Its Application to Wind Turbine Analysis. In Proceedings of the 47th The American Institute of Aeronautics and Astronautics/Aerospace Sciences Meeting (AIAA/ASME), Orlando, FL, USA, 5-10 January 2009.

(C) 2012 by the authors; licensee MDPI, Basel, Switzerland. This article is an open access article distributed under the terms and conditions of the Creative Commons Attribution license (http://creativecommons.org/licenses/by/3.0/). 